\title{
IL-10 and socs3 Are Predictive Biomarkers of Dengue Hemorrhagic Fever
}

\author{
Lilian Karem Flores-Mendoza, ${ }^{1,2}$ Tania Estrada-Jiménez, ${ }^{1,3}$ Virginia Sedeño-Monge, $^{3}$ \\ Margarita Moreno, ${ }^{4}$ María del Consuelo Manjarrez, ${ }^{4}$ Guadalupe González-Ochoa, ${ }^{2}$ \\ Lourdes Millán-Pérez Peña, ${ }^{5}$ and Julio Reyes-Leyva ${ }^{1}$
}

\author{
${ }^{1}$ Centro de Investigación Biomédica de Oriente, HGZ5, Instituto Mexicano del Seguro Social, Km 4.5 Carretera Atlixco-Metepec, \\ 74360 Metepec, PUE, Mexico \\ ${ }^{2}$ Departamento de Ciencias Químico Biológicas y Agropecuarias, División de Ciencias e Ingeniería, Universidad de Sonora, 85880 \\ Navojoa, SON, Mexico \\ ${ }^{3}$ Departamento de Ciencias de la Salud, Universidad Popular Autónoma del Estado de Puebla, 21 Sur 1103, 72410 Puebla, \\ PUE, Mexico \\ ${ }^{4}$ Hospital General de Zona No. 5, Instituto Mexicano del Seguro Social, Km 4.5 Carretera Atlixco-Metepec, 74360 Metepec, \\ PUE, Mexico \\ ${ }^{5}$ Laboratorio de Bioquímica y Biología Molecular, Centro de Química, Instituto de Ciencias, Benemérita Universidad Autónoma de \\ Puebla, Edif. 103 F, CU-BUAP, San Manuel, 72570 Puebla, PUE, Mexico
}

Correspondence should be addressed to Lilian Karem Flores-Mendoza; liliankarem@gmail.com and Julio Reyes-Leyva; jreyesleyva@yahoo.com

Received 13 March 2017; Revised 3 June 2017; Accepted 27 June 2017; Published 30 July 2017

Academic Editor: Giuseppe Valacchi

Copyright (c) 2017 Lilian Karem Flores-Mendoza et al. This is an open access article distributed under the Creative Commons Attribution License, which permits unrestricted use, distribution, and reproduction in any medium, provided the original work is properly cited.

\begin{abstract}
Background. Cytokines play important roles in the physiopathology of dengue infection; therefore, the suppressors of cytokine signaling (socs) that control the type and timing of cytokine functions could be involved in the origin of immune alterations in dengue. Objective. To explore the association of cytokine and socs levels with disease severity in dengue patients. Methods. Blood samples of 48 patients with confirmed dengue infection were analyzed. Amounts of interleukins IL-2, IL-4, IL-6, and IL-10, interferon- (IFN-) $\gamma$, and tumor necrosis factor- (TNF-) $\alpha$ were quantified by flow cytometry, and the relative expression of socs 1 and socs 3 mRNA was quantified by real-time RT-PCR. Results. Increased levels of IL-10 and socs 3 and lower expression of socs1 were found in patients with dengue hemorrhagic fever (DHF) with respect to those with dengue fever (DF) $(p<0.05)$. Negative correlations were found between socs1 and both IL-10 and socs $3(p<0.01)$. The cutoff values of socs3 (>199.8-fold), socs1 $(<1.94$-fold), and IL-10 (>134 pg/ml) have the highest sensitivity and specificity to discriminate between DF and DHF. Conclusion. Simultaneous changes in IL-10 and socs1/socs 3 could be used as prognostic biomarkers of dengue severity.
\end{abstract}

\section{Introduction}

Dengue is one of the most important human viral diseases due to its large morbidity and economic impact $[1,2]$. It is estimated that nearly half of the world's population lives in risk areas of dengue (3.6 billion). The disease causes over 230 million cases of dengue fever, more than 2 million cases of severe disease, and 21,000 deaths $[1,2]$. In addition to the public health and economic cost, there is a major social impact in countries where large dengue epidemics occur, often disrupting primary care services due to the number of hospitalized patients during dengue outbreaks $[1,3]$. Dengue is caused by a single-stranded RNA virus belonging to the Flaviviridae family and genus 
Flavivirus. Dengue virus (DENV) exists as four closely related serotypes.

Dengue symptoms include mild to high degree fever, retroorbital pain, headache, myalgia, arthralgia, rash, nausea, vomiting, abdominal pain, mucosal bleeding, and thrombocytopenia. Patients may deteriorate to severe dengue disease, including DHF and dengue shock syndrome (DSS), characterized by vascular permeability, plasma leakage, severe hemorrhage, and in some cases organ impairment and death [4-6].

The occurrence of DHF/DSS is thought to result from a complex interplay between virus and host immune factors [6]. Some studies found an increased risk of DHF after the second infection with a different serotype mediated by a process known as antibody-dependent enhancement (ADE) of infection and by cross-reactive autoantibodies and $T$ cells $[6-8]$.

Diverse efforts have been made to identify potential predictors of the development of severe disease (DHF/DSS). In those studies, several cytokines have been found elevated in patients with severe dengue compared to dengue without complications. But just a few of them, including IL-10, IL-6, and IFN- $\gamma$, have been proposed as potential predictors of disease severity [8-15].

Cytokines induce the activation of immune cells during infection, and their response is maintained under control by a group of negative regulatory factors, including the suppressors of cytokine signaling (SOCS), which are necessary to stop the cytokine cascade and return to homeostasis $[16,17]$. Of the eight family members, socs 1 and $\operatorname{socs} 3$ are the most potent inhibitors of cytokine signaling mediated by the JAK/STAT pathway $[18,19]$. Overexpression of socs 1 and $\operatorname{socs} 3$ is associated with deregulation of the immune response and the cytokine secretion patterns [16-19]. Several viruses destabilize the host antiviral defense by upregulating $\operatorname{socs} 1$ and $\operatorname{socs} 3$ [20-23].

The association between socs and dengue infection has been scarcely explored [24-29]. Ubol et al. and Tsai et al. reproduced the $\mathrm{ADE}$ phenomenon in cell lines infected with dengue virus in the presence of subneutralizing concentrations of antibodies. Under that condition, dengue virus infection induced more IL-10 and socs 3 expression, but reduced IFN- $\beta$ production $[24,26]$. Rolph et al. studied the ADE phenomenon in human primary macrophages, and they found that IL-6, but not IL-10, induced socs3 expression and JAK-STAT pathway inhibition [25]. Chen et al. found high levels of IL-10 associated to reduce socs1 expression in DHF patients [27]. We have previously found that DENV infection induced high expression of socs 1 and socs 3 in macrophages derived from the U-937 cell line, being socs 1 ten times more expressed than socs3. Those changes were associated with evasion of the antiviral innate immune response in dengue-infected cells [28, 29]. Here, we studied the immune response of patients during the first dengue outbreak identified in Puebla state, in a geographical area that delimits three dengue endemic states, but that differs in height above sea level and climate. We examined biochemical parameters, cytokines, and socs gene expression searching for correlations with dengue severity.

\section{Methods}

2.1. Ethical Statement. This research was approved by the Local Committee of Ethics and Research in Health of the Mexican Institute of Social Security (IMSS); registry number R-2011-2103-24. The study was performed in agreement with the Declaration of Helsinki (last actualization Brazil October 2013). Informed consent was obtained from patients soon after admission. In patients younger than 18 years, informed consent was obtained from their parents or legal custodian. Clinical data and blood samples were recorded with a serial study number to maintain confidentiality.

2.2. Patients' Data Collection and Laboratory Test. The study was done in patients admitted for medical attention for dengue at the General Hospital of Zone No. 5 (HGZ5), IMSS, located in Metepec, Puebla, Mexico, from August 1st to September 1st, 2013. The control group was integrated by healthy subjects from the blood bank of the Hospital of Specialties UMAE, IMSS, located in Puebla City, Mexico, which concentrates patients from a geographical region free of dengue.

Dengue diagnosis was confirmed by identifying the DENV-specific IgM and IgG (Mac-ELISA, PanBio Diagnostic), or the nonstructural protein 1 (NS1) antigen (Platelia Biorad).

As part of the medical attention, blood samples were taken for hematological and biochemical tests such as white blood cell counts, hematocrit, hemoglobin, platelet counts, albumin, aspartate (AST), and alanine (ALT) aminotransferases. Abdominal ultrasound and other tests were requested at a physician's discretion. Patients that completed the clinical history, physical examinations, and clinical laboratory tests and confirmed virus diagnosis were included in the immunological study group.

2.3. Case Classification. Cases were classified as DF and DHF according to WHO 1997 guidelines and hospital's internal directions. DF was defined as laboratory-confirmed cases with high fever without evidence of plasma leakage, with or without hemorrhagic manifestations. DHF was characterized by evidence of plasma leakage associated with the presence of hemorrhagic manifestations (petechia, ecchymosis, rash, or bleeding of the gastrointestinal mucosa, the urinary tract, or other locations) and thrombocytopenia ( $\leq 100,000$ platelets/ $\mathrm{mm} 3$ ) without shock.

2.4. Blood Sampling. For immunological purposes, whole blood samples were obtained either at 6 or 7 days of fever onset. Five $\mathrm{mL}$ of blood was drawn into heparinized tubes and centrifuged at $1700 \mathrm{rpm}$ at $4^{\circ} \mathrm{C}$ for 7 minutes to separate plasma. Aliquots were stored at $-70^{\circ} \mathrm{C}$ until use for flow cytometry. Peripheral blood mononuclear cells (PBMC) were isolated by Ficoll-Hystopaque density gradient centrifugation.

2.5. Flow Cytometry. Cytokine concentrations in plasma were measured with the BD cytometric bead array (CBA) Human Th1/Th2/Th17 Cytokine Kit (BD Biosciences), following the manufacturer's instructions. Samples were analyzed on the BD FACS Canto II Flow Cytometer and analyzed by FCAP 
ArrayTM Software (BD Bioscience). Cytokine standards were serially diluted, and calibration curves were constructed to determine the protein concentrations of the test samples.

2.6. Total RNA Extraction. Total ARN was isolated from PBMC using TRIzol (Invitrogen) according to the manufacturer's instructions. RNA was quantified using a plate reader spectrophotometer Synergy 4 (BioTek). RNA integrity was confirmed by agarose gel electrophoresis.

2.7. Quantitative Real-Time RT-PCR. Expression of socs genes was quantified by real-time RT-PCR. RNA was reverse transcribed using the random primers included in the RevertAid H Minus Reverse Transcriptase kit (Fermentas). The reaction mixture was incubated at $25^{\circ} \mathrm{C}$ for $10 \mathrm{~min}$, $42^{\circ} \mathrm{C}$ for $60 \mathrm{~min}$, and $70^{\circ} \mathrm{C}$ for $10 \mathrm{~min}$. Real-time RT-PCR was performed using SYBR Green/ROX-PCR master mix (Fermentas). RNase P was used as an endogenous expression control in all experiments.

Dynamic range for socs 1 and socs 3 with respect to RNase $P$ was calculated for both genes at 50-200 ng, giving a linear slope of 0.03 and 0.009 , respectively. Assay specificity was confirmed by the dissociation curves corresponding to each gene.

The primers used were socs 1 Forward 5'-CAC GCA CTT CCG CAC ATT CC-3', socs1 Reverse 5'-TCC AGC AGC TCG AAG AGG CA-3', socs3 Forward 5'-ACA ATC TGC CTC AAT CAC TCT G 3', and socs3 Reverse 5'-TTG ACT TGG ATT GGG ATT TTG-3'.

All reactions were run in duplicate by using a StepOne Real-Time PCR system (Applied Biosystems). The mRNA expression level between T0 and Tn was expressed as an $n$-fold increase according to the formula to calculate relative expression $2^{-\Delta \Delta C T} \pm \mathrm{SD}$, where $\Delta \mathrm{CT}$ is the difference in the threshold between any target gene (socs 1 or socs 3 ) and the endogenous gene (RNase $P$ ) and $\Delta \Delta \mathrm{CT}$ establishes the differences between study and control group conditions.

2.8. Statistical Analysis. Demographic and clinical characteristics were compared among subgroups by Mann-Whitney $U$ test for continuous variables and $\chi^{2}$ test for categorical variables. The cytokine concentrations were expressed in $\mathrm{pg} / \mathrm{ml}$ and were compared among groups using the Kruskal-Wallis followed by Dunn's posttest. Correlation coefficients were calculated with Pearson's test when the data had a normal distribution and with Spearman's when they had no normal distribution. A receiver-operating characteristic curve was made. Results were analyzed using GraphPRISM 5.0, and significant differences were considered at $P<0.05$.

\section{Results}

3.1. Demographic Characteristics and Clinic Parameters. According to the hospital records, 73 patients were admitted due to dengue from August 1st to September 1st, 2013. Of these, only 48 patients fulfilled the requirements to be included in the study, accomplished all the clinical, virological, and immunological tests, and gave their informed consent. Based on the WHO classification of 1997, 38 patients presented DF and 10 DHF. Dengue infection was confirmed by measuring plasma levels of IgM in 37 patients, IgG in 7 patients, and NS1 in 4 patients. The age of the patients ranged from 12 to 62 years. The median age for DHF and DF patients was 41 and 31 years, respectively. The main characteristics of the study group are summarized in Table 1.

3.2. Clinical Signs. Most of the patients showed fever, headache, backache, arthralgia, and rash. Physical examinations did not reveal signs of plasma leakage such as ascites, pleural effusion, edema, or ecchymosis in any patient. Several DF patients presented some signs of bleeding: petechia (12/38), epistaxis (5/38), and gingival hemorrhage (3/38) were the most frequent. Most DHF patients presented two or more hemorrhagic signs: $4 / 10$ presented petechiae in combination with epistaxis, hematomas, or gingival hemorrhage; and 3/10 presented a combination of petechiae, epistaxis, and gingival hemorrhage. Hematemesis and melena were less frequent (Table 1).

3.3. Hematological Analyses. Nonsignificant differences were observed between DF and DHF concerning the proportion of leukocytes, lymphocytes, monocytes, and neutrophils. Some parameters were significantly different between DHF and DF patients (Table 1), for example, the hematocrit $(44.8 \pm 5.4$ versus $36.99 \pm 9.94 ; P<0.05)$, hemoglobin $(14.94 \pm 1.86$ versus $12.21 \pm 3.38 ; P<0.05)$, and serum albumin levels $(3.23 \pm 0.58$ versus $2.57 \pm 0.65 ; P<0.01)$. Platelet counts are important hallmarks of dengue disease, and $<10.0 \times 10^{4} / \mathrm{mm} 3$ values are indicative of high risk for hemorrhage. Low platelet counts were found in both DHF $\left(3.9 \pm 2.3 \times 10^{4}\right.$ cells $\left./ \mathrm{mm}^{3}\right)$ and DF patients $\left(5.8 \pm 7 \times 10^{4}\right.$ cells $/ \mathrm{mm}^{3}$ ). Serum ALT levels were higher than the reference values $(30-65 \mathrm{IU} / \mathrm{ml}$ for adults and not more than $48 \mathrm{IU} / \mathrm{ml}$ for children) at $65.73 \pm 29.78 \mathrm{U} / \mathrm{ml}$ in $\mathrm{DF}$ patients and $138 \pm 15.3 \mathrm{U} / \mathrm{ml}$ in DHF patients $(P<0.05)$.

3.4. Patterns of Serum Cytokines. Serum concentrations of IL-2, IL-4, IL-6, IFN- $\gamma$, TNF- $\alpha$, IL-17, and IL-10 were determined in dengue patients at 6 or 7 days of fever onset and were compared with values obtained in a group of healthy controls. Dengue patients showed lower concentrations of IL-2 than controls $(67.94 \pm 3.75 \mathrm{pg} / \mathrm{ml}$ versus $71.59 \pm 1.1 \mathrm{pg} / \mathrm{ml} ; P<0.001)$, but no significant differences in IL-2 between DF and DHF were found (67.86 \pm $3.97 \mathrm{pg} / \mathrm{ml}$ versus $68.23 \pm 2.96 \mathrm{pg} / \mathrm{ml}$, resp.; Figure $1(\mathrm{a})$ ).

IL-10 concentration was higher in dengue patients than in the control group $(112.2 \pm 26.97 \mathrm{pg} / \mathrm{ml}$ versus $59.58 \pm$ $26.03 \mathrm{pg} / \mathrm{ml}$, resp.; $P<0.001)$. In addition, the amount of IL-10 was notably higher in DHF than in DF $(147.65 \pm$ $36.48 \mathrm{pg} / \mathrm{ml}$ versus $102.58 \pm 35.5 \mathrm{pg} / \mathrm{ml}$, resp.; $P<0.001$; Figure 1(b)).

A higher concentration of IL-6 was found in dengue patients compared to the control group $(110.3 \pm 37.88 \mathrm{pg} / \mathrm{ml}$ versus $62.48 \pm 2.47 \mathrm{pg} / \mathrm{ml} ; P<0.001)$. However, there were no significant differences in IL-6 between DF and DHF patients $(111.25 \pm 29.58 \mathrm{pg} / \mathrm{ml}$ versus $106.7 \pm 14.43 \mathrm{pg} / \mathrm{ml}$; Figure 1(c)). 
TABLE 1: Clinical characteristics of dengue patients during the outbreak of Puebla 2013.

\begin{tabular}{|c|c|c|c|c|}
\hline & $\begin{array}{l}\text { All dengue patients } \\
\qquad N=48\end{array}$ & $\begin{array}{c}\mathrm{DF} \\
N=38\end{array}$ & $\begin{array}{c}\text { DHF } \\
N=10\end{array}$ & $P$ values \\
\hline Gender (masculine/feminine) & $24 / 24$ & $21 / 17$ & $3 / 7$ & \\
\hline Mean age (range, years) & $35.75(12-59.5)$ & $31(12-58.5)$ & $41(12.5-62.5)$ & 0.6938 \\
\hline \multicolumn{5}{|l|}{ Laboratory data } \\
\hline Hematocrit (\%) & $43.16 \pm 7.22$ & $44.8 \pm 5.4$ & $36.99 \pm 9.94$ & $0.0351^{*}$ \\
\hline Hemoglobin (g/dl) & $14.37 \pm 2.48$ & $14.94 \pm 1.86$ & $12.21 \pm 3.38$ & $0.0223^{*}$ \\
\hline Platelet count $\left(\times 10^{4}\right.$ cell $\left./ \mathrm{mm} 3\right)$ & $5.41 \pm 6.29^{8}$ & $5.8 \pm 7$ & $3.9 \pm 2.3$ & 0.7702 \\
\hline Albumin (U/ml) & $3 \pm 0.69^{\&}$ & $3.23 \pm 0.58$ & $2.57 \pm 0.65$ & $0.0078^{* *}$ \\
\hline ALT (IU/ml) & $80.05 \pm 47.74^{\&}$ & $65.73 \pm 29.78$ & $138 \pm 15.3$ & $0.0329^{*}$ \\
\hline AST (IU/ml) & $94.05 \pm 59.75^{\&}$ & $89.7 \pm 54.77$ & $165.6 \pm 69.41$ & 0.2179 \\
\hline White blood cells $\left(\times 10^{3}\right.$ cell $\left./ \mathrm{mm}^{3}\right)$ & $5.46 \pm 2.86$ & $5.63 \pm 3.09$ & $4.83 \pm 1.59$ & 0.6221 \\
\hline Lymphocytes (\%) & $34.91 \pm 13.89$ & $33.44 \pm 13.76$ & $40.2 \pm 13.77$ & 0.3634 \\
\hline Monocytes (\%) & $11.96 \pm 6.15$ & $12 \pm 6.42$ & $11.8 \pm 5.37$ & 0.9150 \\
\hline Neutrophils (\%) & $52.37 \pm 17.41$ & $53.61 \pm 17.53$ & $47.9 \pm 17.07$ & 0.3049 \\
\hline \multicolumn{5}{|l|}{ Clinical signs } \\
\hline Petechiae $n(\%)$ & $19(39.58)$ & $12(31.6)$ & $7(70)$ & $0.0271^{*}$ \\
\hline Epistaxis $n(\%)$ & $10(20.83)$ & $5(13.15)$ & $5(50)$ & $0.0107^{*}$ \\
\hline Gingival hemorrhage $n(\%)$ & $7(14.58)$ & $3(7.9)$ & $4(40)$ & $0.0105^{*}$ \\
\hline Hematoma $n(\%)$ & $3(6.25)$ & $1(2.63)$ & $2(20)$ & $0.0435^{*}$ \\
\hline Hematemesis $n(\%)$ & $2(4.16)$ & $1(2.63)$ & $1(10)$ & 0.2995 \\
\hline Melena $n(\%)$ & $2(4.16)$ & $1(2.63)$ & $1(10)$ & 0.2995 \\
\hline
\end{tabular}

Data were obtained during the febrile period of the disease. Laboratory data express the average and standard deviation. Clinical data express the number of patients that presented the sign. $P$ values were determined by Mann-Whitney $U$ test for continuous variables and by the $\chi^{2}$ test for categorical variables. \& means significance with respect to reference values. $*, * *$ mean significance between DF and DHF.

The mean plasma concentrations of TNF- $\alpha$ were $47.62 \pm$ $2.83 \mathrm{pg} / \mathrm{ml}$ for the control group, $46.80 \pm 3.26 \mathrm{pg} / \mathrm{ml}$ for $\mathrm{DF}$, and $50.07 \pm 4.63 \mathrm{pg} / \mathrm{ml}$ for $\mathrm{DHF}$ patients $(P<0.05$; Figure $1(\mathrm{~d}))$. There were no significant differences in IFN- $\gamma$ or IL- 4 values between the control group and dengue patients or between DF and DHF patients (Figures 1(e) and 1(f)). IL-17 was also evaluated, but the results were under the limit of detection of this assay $(20 \mathrm{pg} / \mathrm{ml})$.

3.5. Expression of socs 1 and socs3. The relative expression of socs 1 and socs 3 genes in dengue patients was compared with their expression in the healthy control group, which was assigned an arbitrary value of 1 . socs 1 showed a significantly lower expression in DHF with respect to DF (1.24 \pm 0.85 -fold versus $4.34 \pm 1.96$-fold, resp.; $P<0.01$; Figure 2 (a)).

The relative expression of socs 3 was higher than that of socs 1 in all the patients. In addition, socs 3 expression was directly proportional to disease severity. The relative expression of socs3 was $118.24 \pm 94.57$-fold for DF and $294.33 \pm$ 110.67-fold for DHF $(P<0.0198$; Figure 2(b)).

3.6. Correlation Analysis. Correlation coefficients were calculated between socs 1 and socs 3 expression levels, the concentrations of cytokines, and each biochemical data. Three correlations were statistically relevant: the negative correlation between IL-10 concentration and socs 1 (Spearman's $r=-0.59, P<0.01$; Figure $3(\mathrm{a}))$, the negative correlation between socs 3 and socs 1 (Pearson's $r=-0.48, P<0.01$; Figure 3(b)), and the positive correlation between IL-10 and lymphocyte counts (Spearman's $r=0.42, P<0.05$ ). All the other correlations were minimal $(r<0.4)$ or without significance.

3.7. Potential Biomarkers for Diagnosis and Prediction of Dengue Severity. The progress of dengue fever to its severe forms is one of the most concerning aspects of the disease, and there is no consensus biomarker for its prediction. As an approach, we employed an AUC (area under the curve) analysis to identify the potential of some parameters to discriminate between healthy and dengue-infected subjects, as well as between DF and DHF. IL-10, platelets, and IL-6 seemed to have a better diagnostic potential to discriminate between healthy and dengue patients, with $100 \%$ of specificity (SP) and $90.48 \%, 93.75 \%$, and $95.24 \%$ of sensitivity (SE), respectively, for the cutoffs of $>63$ and $>67 \mathrm{pg} / \mathrm{ml}$ for IL-10 and IL- 6 and $<13.6 \times 10^{4}$ cell $/ \mathrm{mm}^{3}$ for platelets (Table 2 ).

ALT, socs3, IL-10, and socs1 showed the best potential to predict dengue severity. ALT has $100 \%$ SE and $86 \%$ SP at a cutoff of $>93.5 \mathrm{UI} / \mathrm{ml}$. socs 3 has $85 \%$ SE and $86 \%$ SP at a cutoff of $>199.8$-fold. IL- 10 has $77 \%$ SE and $86 \%$ SP at a cutoff of $>134 \mathrm{pg} / \mathrm{ml}$, and socs 1 has $85 \%$ SE and $72 \%$ SP at a cutoff of $<1.948$-fold (Table 3 ). The ROC curves were plotted, and their values indicate a good discrimination between DF and DHF (Figure 4). These analyses suggested that 


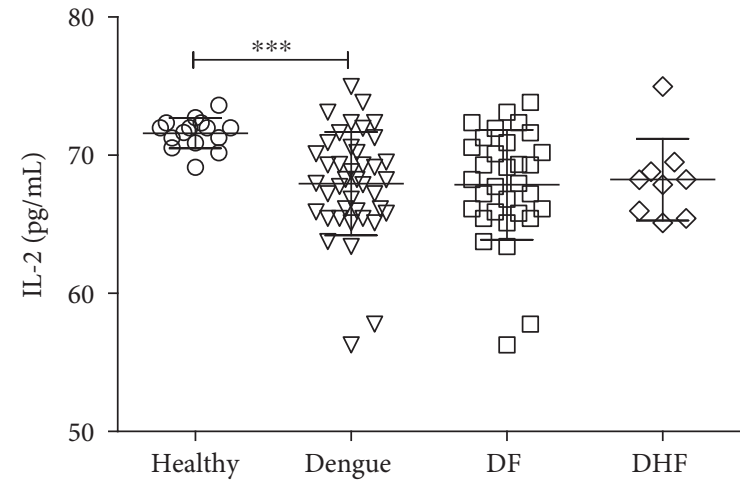

(a)

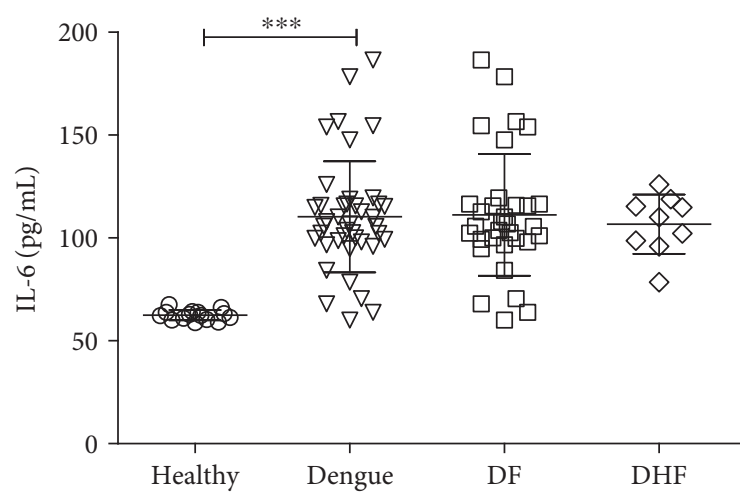

(c)

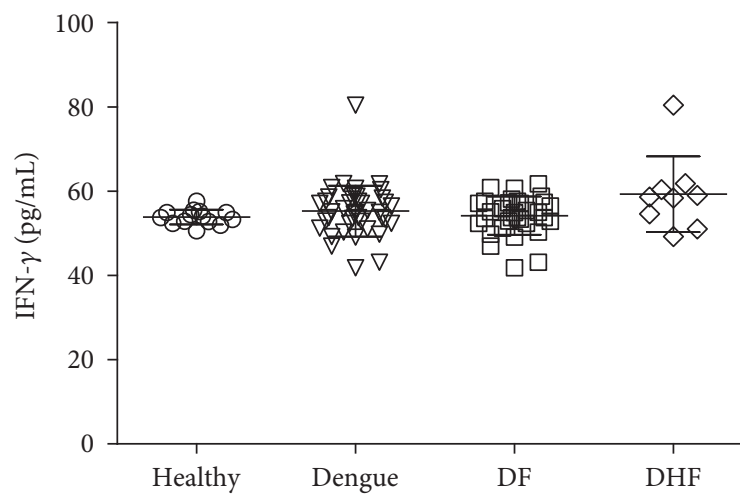

(e)

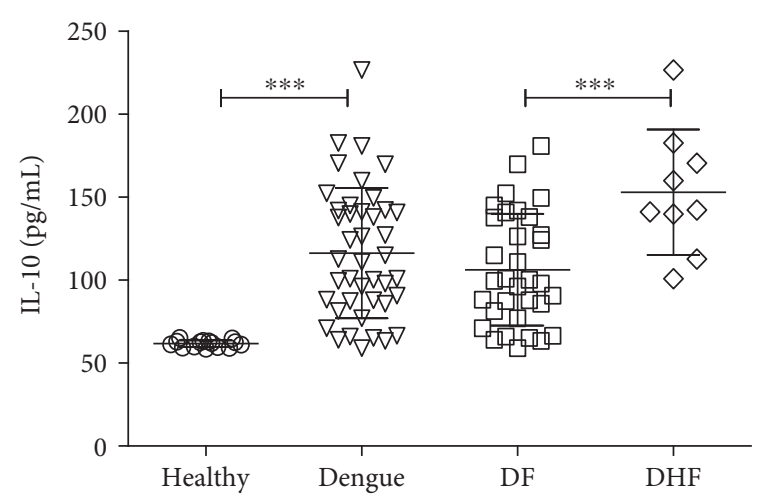

(b)

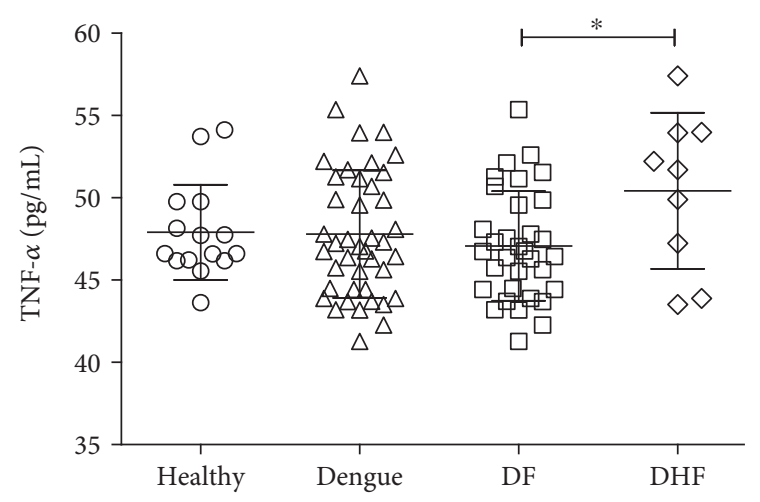

(d)

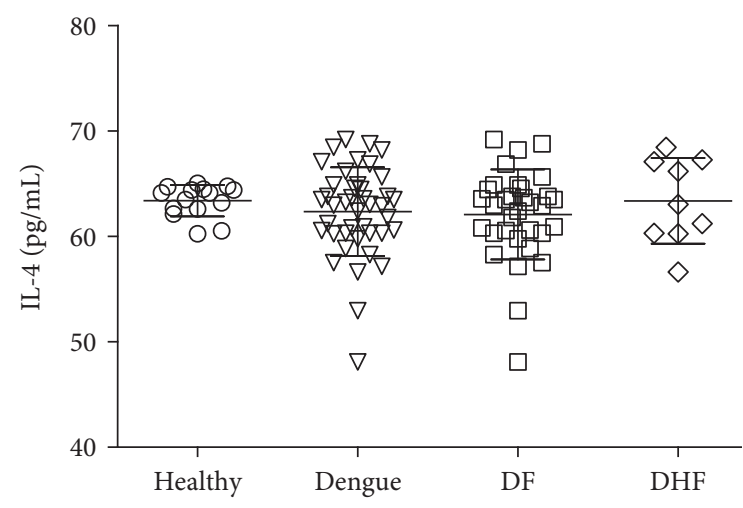

(f)

FIGURE 1: Cytokine concentrations in patients with dengue. Cytokines were determined by cytometric bead array in the blood plasma of the healthy subjects, in all patients with dengue, in DF, and DHF. Results show the values of all subjects belonging to each group; error bars represent mean \pm S.D. Significant differences ${ }^{*} P<0.05$; ${ }^{* *} P<0.001$ by Mann-Whitney $U$ test for continuous variables.

measuring these molecules in combination might contribute to predict disease severity. In this sense, the combination of IL-10 with socs1 and socs3 at the cutoffs mentioned might constitute a significant and biologically important biomarker of dengue severity at early stages of infection.

\section{Discussion}

Numerous factors are implicated in the progress of severe dengue disease such as viral load, serotype, and virulence, as well as genetic and immune host factors [8, 12, 30-34]. Several studies have evaluated the potential of clinical parameters in the prediction of severe dengue progress [35-38]. However, there is no consensus on the laboratory profiles that indicate dengue severity, given the significant variables introduced by local virus evolution, the intricacies of virus-host interactions, the geographical spread of the disease, the regional host genetics, and the stage of illness during sampling. Most research groups report the association of clinical manifestations with increased liver enzymes and albumin levels [38], as well as with leukocyte, hematocrit, and platelet counts [12, 36, 37]. In our study, increased liver enzymes and albumin levels correlated with severe dengue. 


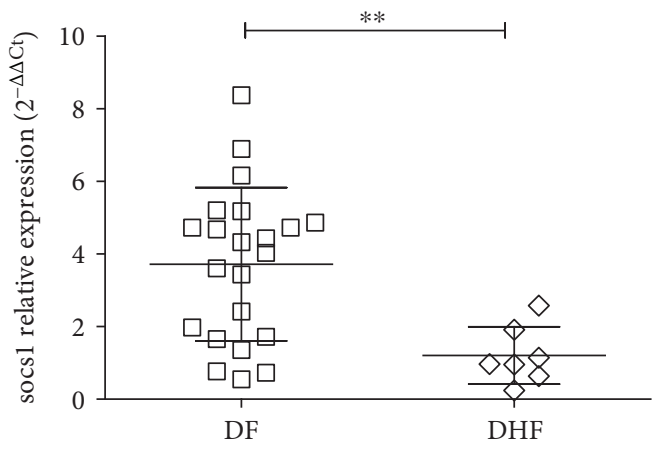

(a)

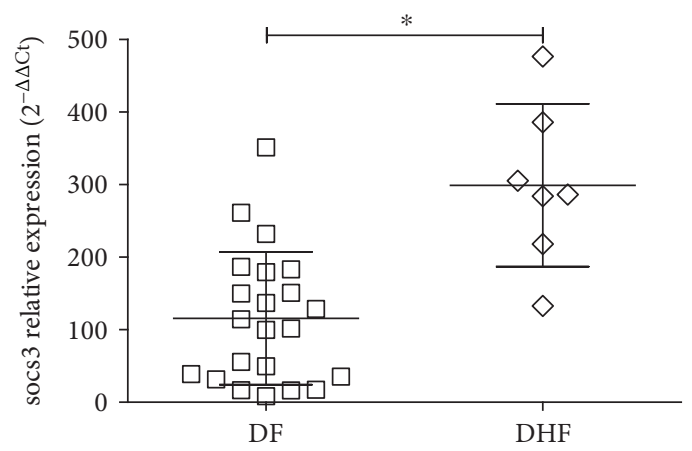

(b)

FIGURE 2: Relative expression of socs genes in patients with dengue. The relative expression of socs 1 and $\operatorname{socs} 3$ mRNA was determined in PBMC of patients with DF and DHF. Results are expressed as fold increments compared with the expression level of the control group which was assigned an arbitrary value of 1 . Error bars represent mean \pm S.D. Significant differences ${ }^{*} P<0.05$; ${ }^{* *} P<0.01$ by MannWhitney $U$ test for continuous variables.

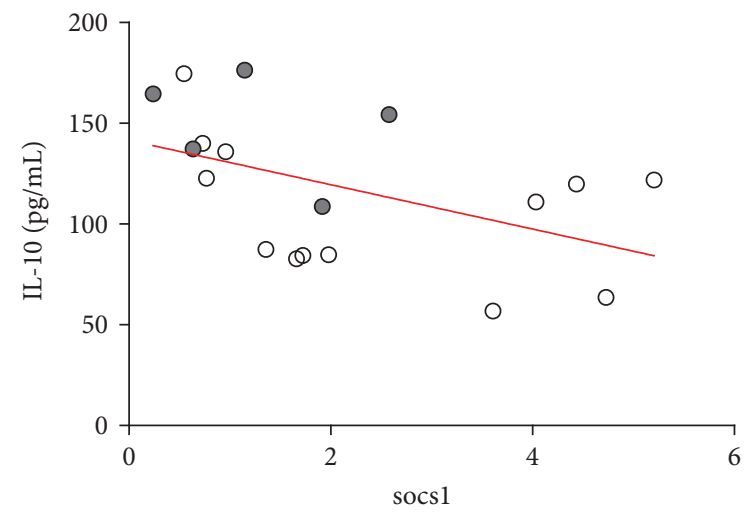

(a)

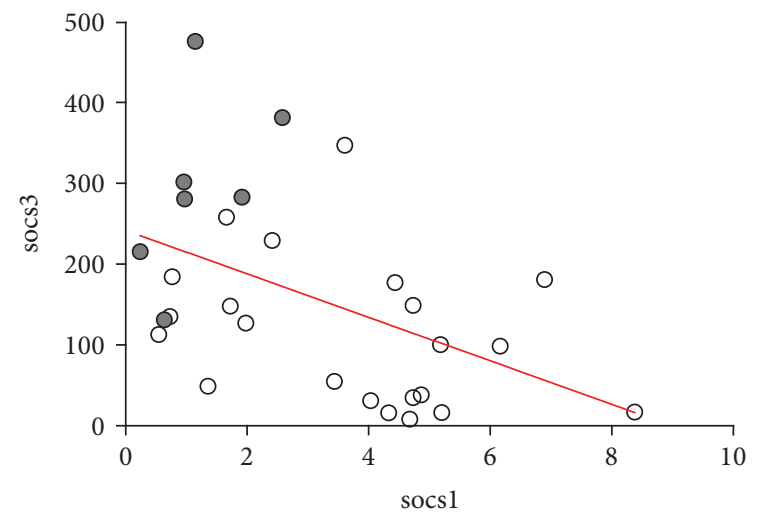

(b)

Figure 3: Correlation analysis between $\operatorname{socs} 1, \operatorname{socs} 3$, and IL-10. Spearman's and Pearson's correlation coefficients were calculated to identify the association between IL-10 concentration and socs1 expression (a) and between socs3 and socs1 expression levels (b).

TABle 2: Potential biomarkers to discriminate healthy from dengue patients.

\begin{tabular}{lcccccc}
\hline & AUC & $95 \%$ CI & $P$ value & Cutoff & Sensitivity \% & Specificity \% \\
\hline IL-10 & 0.9683 & $0.9222-1.014$ & 0.0001 & $>63.25 \mathrm{pg} / \mathrm{ml}$ & 90.48 & 100 \\
IL-6 & 0.9730 & $0.9311-1.015$ & 0.0001 & $>67.77 \mathrm{pg} / \mathrm{ml}$ & 95.24 & 100 \\
Platelets & 0.9742 & $0.9362-1.012$ & 0.0001 & $<13.6 \times 10^{4} / \mathrm{mm}^{3}$ & 93.75 & 78.38 \\
Albumin & 0.7594 & $0.5743-0.9245$ & 0.0128 & $<3.55 \mathrm{UI} / \mathrm{ml}$ & 83.33 & 63.64 \\
ALT & 0.9315 & $0.8263-1.037$ & 0.0001 & $>42.5 \mathrm{UI} / \mathrm{ml}$ & 88.89 & 100 \\
AST & 0.9167 & $0.8008-1.032$ & 0.0001 & $>31.5 \mathrm{UI} / \mathrm{ml}$ & 93.75 \\
\hline
\end{tabular}

AUC analysis was done to identify parameters that can discriminate between healthy and sick dengue-infected patients. Sensitivity and specificity values are calculated on the base of the cutoff of each tested parameter.

Several studies have associated the increased levels of cytokines with altered vascular permeability, plasma leakage, coagulopathy, and thrombocytopenia $[6,11,14,39-44]$. However, there is still much controversy about the role of specific cytokines in determining the progress of DF to DHF, because the levels of these cytokines varied during the febrile and the critical phases $[9,14,32,39,41,45,46]$. TNF- $\alpha$ and IFN- $\gamma$ are recognized as two of the most important factors associated to dengue progress $[9,34,39]$. IFN- $\gamma$ seems to be relevant in the response to secondary infections $[8,34]$. However, there were no differences in IFN- $\gamma$ in our study, although we did not distinguish between primary 
TABLE 3: Potential biomarkers to identify severity of dengue infection.

\begin{tabular}{|c|c|c|c|c|c|c|}
\hline & AUC & $95 \%$ CI & $P$ value & Cutoff & Sensitivity \% & Specificity \% \\
\hline IL-10 & 0.8519 & $0.6922-1.011$ & 0.0046 & $>134 \mathrm{pg} / \mathrm{ml}$ & 77.78 & 86.67 \\
\hline IL-6 & 0.5266 & $0.3120-0.7412$ & 0.8177 & $<136.8 \mathrm{pg} / \mathrm{ml}$ & 100 & 17.39 \\
\hline Platelets & 0.5316 & $0.3400-0.7231$ & 0.7607 & $<9.05 \times 10^{4} / \mathrm{ml}$ & 100 & 15.79 \\
\hline Albumin & 0.7976 & $0.6942-0.9461$ & 0.0079 & $<3.55 \mathrm{UI} / \mathrm{ml}$ & 88.89 & 57.14 \\
\hline ALT & 0.9111 & $0.7682-1.054$ & 0.0284 & $>93.5 \mathrm{UI} / \mathrm{ml}$ & 100 & 86.67 \\
\hline AST & 0.8000 & $0.5367-1.063$ & 0.1098 & $>140 \mathrm{UI} / \mathrm{ml}$ & 86.67 & 66.67 \\
\hline socs 1 & 0.8441 & $0.7006-0.9877$ & 0.0069 & $<1.94$-fold & 85.71 & 72.73 \\
\hline socs 3 & 0.9026 & $0.7777-1.028$ & 0.0016 & $>199.8$-fold & 85.71 & 86.36 \\
\hline
\end{tabular}

AUC analysis was done to explore the potential of each parameter to predict dengue severity by comparing between DF and DHF patients. socs3, socs1, IL-10, and ALT have the best predictive values.

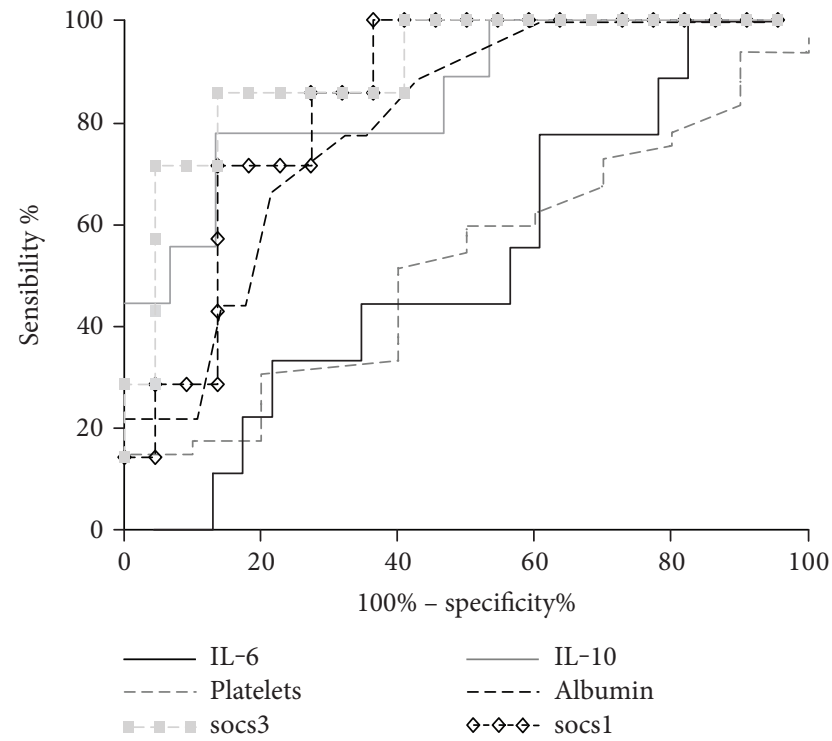

Figure 4: Predictive analysis of immunological biomarkers to identify dengue severity. The ROC curves were plotted using the sensitivity and specificity data and the cutoff values presented in Table 3, with the software GraphPad Prism 5. soc3, socs1, IL-10, and albumin discriminate between DF and DHF.

and secondary infections. On the other hand, we found a slight increase in TNF- $\alpha$ in DHF patients. TNF- $\alpha$ has been found in a broad concentration range in dengue patients $[34,41,42]$, that is, influenced by the time of blood sampling and TNF- $\alpha$ 's genetic polymorphisms $[47,48]$. This variability makes TNF- $\alpha$ a nonideal marker for disease severity.

High concentrations of IL-6 were found in dengue patients in our study, and this is consistent with most studies [31, 42, 49-51]. IL-6 has been associated with the increment of vascular permeability, plasma leakage, pleural effusion, and ascites [41, 51, 52]. IL-6 induces leukocyte recruitment, local inflammation, and damage to endothelial cells. Thus, high levels of IL- 6 correlate with a fatal outcome for DHF/DSS [43, 53].

Elevated IL-10 has been a consistent finding in patients with severe dengue. This led to propose IL-10 as a prognostic biomarker of DHF/DSS [11, 12, 26, 27, 34, 54]. The biological role of IL-10 in dengue pathogenesis is not fully known; it has been associated with changes in vascular permeability, plasma leakage, thrombocytopenia, and altered levels of hepatic transaminases $[7,8,12,40,55-58]$. However, the immunosuppressive function of IL-10 could be a major determinant of its contribution to dengue pathogenesis. IL-10 activates socs 3 expression that inhibits the signaling pathways induced by IL-6, IL-2, IL-12, IFN- $\gamma$, and NF-kB. In turn, an increase in socs 3 is associated with induction of Th2 cells and inhibition of the Th1 response $[19,55,56]$. Overexpression of IL-10 and socs 3 was associated with the $\mathrm{ADE}$ phenomenon in monocytes and macrophages infected with the dengue virus [24-26]. We found a high expression of IL-10 and socs 3 in patients with severe dengue. Our results confirm in a larger population and a more quantitative way the results reported by Ubol et al. [24], supporting binomial IL-10/socs3 determination as a severe dengue biomarker.

socs1 is another negative regulator of cytokine signaling affected by dengue infection $[28,29]$. Chen et al. reported a decrease in socs1 expression in DHF with respect to DF patients, which was associated with low levels of IFN- $\gamma$ and high levels of IL-10 during defervescence [27], similar to our results. Low expression of socs1 seems to be associated to the $\mathrm{ADE}$ of infection phenomenon in cell cultures $[24,25,35]$. However, the presence of $\mathrm{ADE}$ is difficult to ascertain in patients.

Our results seem controversial because we found high levels of IL- 6 and IL-10 in DHF patients. IL-10 is the major anti-inflammatory cytokine, and IL-6 is a potent proinflammatory factor. Both can block IFN- $\alpha$ activity by inducing socs3 [25]. socs3 is expressed by a feedback signal in response to IL-6, which led to a downregulation of IL-6 response and synthesis [44]. We have previously found that socs3 overexpression in dengue-infected cells contributes to evasion of the innate immune response $[28,29]$. In agreement, simultaneous increase of IL- 6 and IL-10 in DHF is indicative of the dysregulated immune response that leads to the progress of dengue severity [49]. The changes in cytokine expression found in this study suggest that deregulation of socs 1 and socs 3 expression induced by dengue virus infection [28, 29] is not just involved in cytokine imbalance but also promotes the persistent inflammatory response that contributes to increased vascular permeability and hemorrhagic 
manifestations. However, further mechanistic studies are required to clarify how these regulatory factors are altered during dengue infection.

\section{Conclusion}

This study evidenced the association of socs 1 and $\operatorname{socs} 3$ with the imbalance of cytokine response found in severe dengue patients. Our results suggest that the combined analysis of socs 1 , socs 3 , IL-10, and IL-6 could identify patients at risk of severe dengue.

\section{Abbreviations}

DENV: Dengue virus

PBMC: Peripheral blood mononuclear cell

SOCS: Suppressor of cytokine signaling

NS1: $\quad$ Nonstructural protein 1

TNF- $\alpha$ : Tumor necrosis factor alpha

IFN- $\alpha$ : Interferon-alpha

IFN- $\gamma$ : Interferon-gamma

RT-PCR: Reverse transcription-polymerase chain reaction

DF: $\quad$ Dengue fever

DHF: Dengue hemorrhagic fever

DSS: Dengue shock syndrome

MIP-1: Macrophage inflammatory protein-1

STAT: $\quad$ Signal transducers and activators of transcription

JAK: Janus kinase

NF-kB: Nuclear factor $\mathrm{kB}$

FBS: $\quad$ Fetal bovine serum

CT: $\quad$ Cycle threshold.

\section{Conflicts of Interest}

The authors declare that they have no competing interests.

\section{Authors' Contributions}

Tania Estrada-Jiménez participated in the clinical data collecting, carried out the RT-PCR studies, and drafted the manuscript. Virginia Sedeño-Monge participated in the analysis of the quantitative RT-PCR data and helped with the statistical analysis. Margarita Moreno and María del Consuelo Manjarrez were in direct contact with the patients and performed the laboratory tests and the clinical data analysis. Lourdes Millán-Pérez Peña helped with the evaluation of IL-10 and revised the manuscript. Guadalupe González-Ochoa helped with the statistical analysis. Lilian Karem Flores-Mendoza designed and got funds for the study; she participated in the clinical data collecting, carried out the cytokine determinations, performed the statistical analysis, and drafted the manuscript. Julio Reyes-Leyva participated in the design of the study and wrote the final version of the paper. All the authors approved the final manuscript.

\section{Acknowledgments}

Tania Estrada-Jiménez had a scholarship from CONACYT (no. 209881) and IMSS (98220625). The study was supported by IMSS (grant FIS/IMSS/PROT/G11/980 and
CTFIS/10RD/12/2011) and by Redes Temáticas-SEP (BUAP-CA-147). Julio Reyes-Leyva has a research fellowship from Fundación IMSS A.C. None of these institutions participate, determine, or interfere in any form with the design and development of the study, decision to publish, or preparation of the manuscript. The authors acknowledge all the patients and medical staff of Hospital General de Zona No. 5 IMSS Metepec, Puebla, particularly to QFB Patricia Garrido, QFB Erica Plata, and QFB Blanca Bañuelos for her technical assistance. Special thanks are due to Paulina Cortés for the grammatical revision of the manuscript.

\section{References}

[1] D. J. Gubler, "The economic burden of dengue," The American Journal of Tropical Medicine and Hygiene, vol. 86, no. 5, pp. 743-744, 2012

[2] M. E. Beatty, L. G. Margolis, and H. S. Phuket, “"Thailand, 2008: estimating the global burden of dengue. Abstract book: dengue", 2008," Proceedings of the 2nd International Conference on Dengue and Dengue Haemorrhagic Fever, Phuket, Thailand, 2008.

[3] E. A. Undurraga, M. Betancourt-Cravioto, J. Ramos-Castaneda et al., "Economic and disease burden of dengue in Mexico," PLoS Neglected Tropical Diseases, vol. 9, no. 3, article e0003547, 2015.

[4] WHO, Dengue Haemorrhagic Fever: Diagnosis, Treatment, and Control, World Health Organization, Geneva, 1997.

[5] WHO, Dengue: Guidelines for Diagnosis, Treatment, Prevention and Control, new Edition, World Health Organization, Geneva, 2009.

[6] B. E. Martina, P. Koraka, and A. D. Osterhaus, "Dengue virus pathogenesis: an integrated view," Clinical Microbiology Reviews, vol. 22, no. 4, pp. 564-581, 2009.

[7] S. Green and A. Rothman, "Immunopathological mechanisms in dengue and dengue hemorrhagic fever," Current Opinion in Infectious Diseases, vol. 19, no. 5, pp. 429-436, 2006.

[8] A. L. Rothman, "Immunity to dengue virus: a tale of original antigenic sin and tropical cytokine storms," Nature Reviews. Immunology, vol. 11, no. 8, pp. 532-543, 2011.

[9] Y. Kumar, C. Liang, Z. Bo, J. C. Rajapakse, E. E. Ooi, and S. R. Tannenbaum, "Serum proteome and cytokine analysis in a longitudinal cohort of adults with primary dengue infection reveals predictive markers of DHF," PLoS Neglected Tropical Diseases, vol. 6, no. 11, article e1887, 2012.

[10] F. A. Bozza, O. G. Cruz, S. M. Zagne et al., "Multiplex cytokine profile from dengue patients: MIP-1beta and IFN-gamma as predictive factors for severity," BMC Infectious Diseases, vol. 8 , p. 86, 2008 .

[11] G. N. Malavige, L. Gomes, L. Alles et al., "Serum IL-10 as a marker of severe dengue infection," BMC Infectious Diseases, vol. 13, no. 1, p. 341, 2013.

[12] A. R. Brasier, H. Ju, J. Garcia et al., "A three-component biomarker panel for prediction of dengue hemorrhagic fever," The American Journal of Tropical Medicine and Hygiene, vol. 86, no. 2, pp. 341-348, 2012.

[13] T. H. Nguyen, H. Y. Lei, T. L. Nguyen et al., "Dengue hemorrhagic fever in infants: a study of clinical and cytokine profiles," The Journal of Infectious Diseases, vol. 189, no. 2, pp. 221-232, 2004. 
[14] P. Butthep, S. Chunhakan, S. Yoksan, K. Tangnararatchakit, and A. Chuansumrit, "Alteration of cytokines and chemokines during febrile episodes associated with endothelial cell damage and plasma leakage in dengue hemorrhagic fever," The Pediatric Infectious Disease Journal, vol. 31, no. 12, pp. e232-e238, 2012.

[15] J. Arias, N. Valero, J. Mosquera et al., "Increased expression of cytokines, soluble cytokine receptors, soluble apoptosis ligand and apoptosis in dengue," Virology, vol. 452, pp. 42-51, 2014.

[16] L. N. Akhtar and E. N. Benveniste, "Viral exploitation of host SOCS protein functions," Journal of Virology, vol. 85, no. 5, pp. 1912-1921, 2011.

[17] W. S. Alexander and D. J. Hilton, "The role of suppressors of cytokine signaling (SOCS) proteins in regulation of the immune response," Annual Review of Immunology, vol. 22, pp. 503-529, 2004.

[18] B. Carow and M. E. Rottenberg, "SOCS3, a major regulator of infection and inflammation," Frontiers in Immunology, vol. 5, p. $58,2014$.

[19] I. D. Dimitriou, L. Clemenza, A. J. Scotter, G. Chen, F. M. Guerra, and R. Rottapel, "Putting out the fire: coordinated suppression of the innate and adaptive immune systems by SOCS1 and SOCS3 proteins," Immunological Reviews, vol. 224, pp. 265-283, 2008.

[20] S. Yokota, N. Yokosawa, T. Okabayashi et al., "Induction of suppressor of cytokine signaling-3 by herpes simplex virus type 1 contributes to inhibition of the interferon signaling pathway," Journal of Virology, vol. 78, no. 12, pp. 62826286, 2004.

[21] C. M. Oshansky, T. M. Krunkosky, J. Barber, L. P. Jones, and R. A. Tripp, "Respiratory syncytial virus proteins modulate suppressors of cytokine signaling 1 and 3 and the type I interferon response to infection by a toll-like receptor pathway," Viral Immunology, vol. 22, no. 3, pp. 147-161, 2009.

[22] J. Pothlichet, M. Chignard, and M. Si-Tahar, "Cutting edge: innate immune response triggered by influenza $\mathrm{A}$ virus is negatively regulated by SOCS1 and SOCS3 through a RIGI/IFNAR1-dependent pathway," Journal of Immunology, vol. 180, no. 4, pp. 2034-2038, 2008.

[23] A. S. Collins, S. Ahmed, S. Napoletano et al., "Hepatitis C virus (HCV)-induced suppressor of cytokine signaling (SOCS) 3 regulates proinflammatory TNF-alpha responses," Journal of Leukocyte Biology, vol. 96, no. 2, pp. 255-263, 2014.

[24] S. Ubol, W. Phuklia, S. Kalayanarooj, and N. Modhiran, "Mechanisms of immune evasion induced by a complex of dengue virus and preexisting enhancing antibodies," The Journal of Infectious Diseases, vol. 201, no. 6, pp. 923-935, 2010.

[25] M. S. Rolph, A. Zaid, N. E. Rulli, and S. Mahalingam, "Downregulation of interferon-beta in antibody-dependent enhancement of dengue viral infections of human macrophages is dependent on interleukin-6," The Journal of Infectious Diseases, vol. 204, no. 3, pp. 489-491, 2011.

[26] T. T. Tsai, Y. J. Chuang, Y. S. Lin et al., “Antibody-dependent enhancement infection facilitates dengue virus-regulated signaling of IL-10 production in monocytes," PLoS Neglected Tropical Diseases, vol. 8, no. 11, article e3320, 2014.

[27] R. F. Chen, K. D. Yang, I. K. Lee et al., “Augmented miR-150 expression associated with depressed SOCS1 expression involved in dengue haemorrhagic fever," The Journal of Infection, vol. 69, no. 4, pp. 366-374, 2014.
[28] T. Estrada-Jimenez, L. Millan-Perez Pena, L. Flores-Mendoza et al., "Upregulation of the suppressors of cytokine signaling 1 and 3 is associated with arrest of phosphorylated-STAT1 nuclear importation and reduced innate response in dengue virus-infected macrophages," Viral Immunology, vol. 29, no. 2, pp. 95-104, 2016.

[29] H. K. Palma-Ocampo, J. C. Flores-Alonso, V. Vallejo-Ruiz et al., "Interferon lambda inhibits dengue virus replication in epithelial cells," Virology Journal, vol. 12, p. 150, 2015.

[30] P. Thakur, A. Chakravarti, S. Aggarwal, B. Uppal, and P. Bhalla, "Elevated levels of vascular endothelial growth factor in adults with severe dengue infection," Virus Disease, vol. 27, no. 1, pp. 48-54, 2016.

[31] S. B. Halstead, "Controversies in dengue pathogenesis," Paediatrics and International Child Health, vol. 32, Supplement 1, pp. 5-9, 2012.

[32] S. Fernando, A. Wijewickrama, L. Gomes et al., "Patterns and causes of liver involvement in acute dengue infection," BMC Infectious Diseases, vol. 16, p. 319, 2016, 5.

[33] T. H. Lee, L. K. Lee, D. C. Lye, and Y. S. Leo, "Current management of severe dengue infection," Expert Review of Anti-Infective Therapy, vol. 15, no. 1, pp. 67-78, 2017.

[34] A. Rathakrishnan, S. M. Wang, Y. Hu et al., "Cytokine expression profile of dengue patients at different phases of illness," PloS One, vol. 7, no. 12, article e52215, 2012.

[35] S. Yacoub, P. K. Lam, H. M. Vu le et al., "Association of microvascular function and endothelial biomarkers with clinical outcome in dengue: an observational study," The Journal of Infectious Diseases, vol. 214, no. 5, pp. 697-706, 2016.

[36] S. Yacoub and B. Wills, "Predicting outcome from dengue," BMC Medicine, vol. 12, no. 1, p. 147, 2014.

[37] T. Jaenisch, D. T. Tam, N. T. Kieu et al., "Clinical evaluation of dengue and identification of risk factors for severe disease: protocol for a multicentre study in 8 countries," $B M C$ Infectious Diseases, vol. 16, p. 120, 2016.

[38] M. Mahmuduzzaman, A. S. Chowdhury, D. K. Ghosh, I. M. Kabir, M. A. Rahman, and M. S. Ali, "Serum transaminase level changes in dengue fever and its correlation with disease severity," Mymensingh Medical Journal, vol. 20, no. 3, pp. 349-355, 2011.

[39] R. Appanna, S. M. Wang, S. A. Ponnampalavanar, L. C. Lum, and S. D. Sekaran, "Cytokine factors present in dengue patient sera induces alterations of junctional proteins in human endothelial cells," The American Journal of Tropical Medicine and Hygiene, vol. 87, no. 5, pp. 936-942, 2012.

[40] U. C. Chaturvedi, R. Agarwal, E. A. Elbishbishi, and A. S. Mustafa, "Cytokine cascade in dengue hemorrhagic fever: implications for pathogenesis," FEMS Immunology and Medical Microbiology, vol. 28, no. 3, pp. 183-188, 2000.

[41] D. Priyadarshini, R. R. Gadia, A. Tripathy et al., "Clinical findings and pro-inflammatory cytokines in dengue patients in Western India: a facility-based study," PloS One, vol. 5, no. 1, article e8709, 2010.

[42] G. N. Malavige, L. C. Huang, M. Salimi, L. Gomes, S. D. Jayaratne, and G. S. Ogg, "Cellular and cytokine correlates of severe dengue infection," PloS One, vol. 7, no. 11, article e50387, 2012.

[43] D. B. Bethell, K. Flobbe, X. T. Cao et al., "Pathophysiologic and prognostic role of cytokines in dengue hemorrhagic fever," The Journal of Infectious Diseases, vol. 177, no. 3, pp. 778782, 1998. 
[44] G. Levidou, S. Sachanas, G. A. Pangalis et al., "Immunohistochemical analysis of IL-6, IL-8/CXCR2 axis, Tyr p-STAT-3, and SOCS-3 in lymph nodes from patients with chronic lymphocytic leukemia: correlation between microvascular characteristics and prognostic significance," BioMed Research International, vol. 2014, Article ID 251479, 13 pages, 2014.

[45] R. Soundravally, S. L. Hoti, S. A. Patil et al., "Association between proinflammatory cytokines and lipid peroxidation in patients with severe dengue disease around defervescence," International Journal of Infectious Diseases, vol. 18, pp. 6872, 2014.

[46] S. Green, D. W. Vaughn, S. Kalayanarooj et al., "Early immune activation in acute dengue illness is related to development of plasma leakage and disease severity," The Journal of Infectious Diseases, vol. 179, no. 4, pp. 755-762, 1999.

[47] M. T. Fernandez-Mestre, K. Gendzekhadze, P. RivasVetencourt, and Z. Layrisse, "TNF-alpha-308A allele, a possible severity risk factor of hemorrhagic manifestation in dengue fever patients," Tissue Antigens, vol. 64, no. 4, pp. 469-472, 2004.

[48] R. Gupta, V. Kapuria, and S. N. Das, "Single nucleotide polymorphisms in TNF-alpha, TNFR2 gene and TNF-alpha production in Asian Indians," Immunological Investigations, vol. 38, no. 3-4, pp. 240-254, 2009.

[49] B. N. Restrepo, D. M. Isaza, C. L. Salazar, R. Ramirez, M. Ospina, and L. G. Alvarez, "Serum levels of interleukin-6, tumor necrosis factor-alpha and interferon-gamma in infants with and without dengue," Revista da Sociedade Brasileira de Medicina Tropical, vol. 41, no. 1, pp. 6-10, 2008.

[50] S. Eppy, L. Nainggolan, and C. M. Rumende, "The differences between interleukin- 6 and C-reactive protein levels among adult patients of dengue infection with and without plasma leakage," Acta Medica Indonesiana, vol. 48, no. 1, pp. 3-9, 2016.

[51] B. Sierra, A. B. Perez, M. Alvarez et al., "Variation in inflammatory/regulatory cytokines in secondary, tertiary, and quaternary challenges with dengue virus," The American Journal of Tropical Medicine and Hygiene, vol. 87, no. 3, pp. 538-547, 2012.

[52] Y. H. Huang, H. Y. Lei, H. S. Liu, Y. S. Lin, C. C. Liu, and T. M. Yeh, "Dengue virus infects human endothelial cells and induces IL-6 and IL-8 production," The American Journal of Tropical Medicine and Hygiene, vol. 63, no. 1-2, pp. 7175, 2000.

[53] L. C. Chen, H. Y. Lei, C. C. Liu et al., "Correlation of serum levels of macrophage migration inhibitory factor with disease severity and clinical outcome in dengue patients," The American Journal of Tropical Medicine and Hygiene, vol. 74, no. 1, pp. 142-147, 2006.

[54] A. Ranchman and I. Rinaldi, "Coagulopathy in dengue infection and the role of interleukin-6," Acta Medica Indonesiana, vol. 38, no. 2, pp. 105-108, 2006.

[55] M. Kubo and H. Inoue, "Suppressor of cytokine signaling 3 (SOCS3) in Th2 cells evokes Th2 cytokines, IgE, and eosinophilia," Current Allergy and Asthma Reports, vol. 6, no. 1, pp. 32-39, 2006.

[56] D. H. Libraty, T. P. Endy, H. S. Houng et al., "Differing influences of virus burden and immune activation on disease severity in secondary dengue-3 virus infections," The Journal of Infectious Diseases, vol. 185, no. 9, pp. 1213-1221, 2002.

[57] C. E. Egwuagu, C. C. Y. Yu, M. Zhang, R. M. Mahdi, J. K. Stephen, and I. Gery, "Suppressors of cytokine signaling proteins are differentially expressed in Th1 and Th2 cells: implications for Th1 and Th2 commitment and maintenance," The Journal of Immunology, vol. 168, pp. 3181-2187, 2002.

[58] A. Torrentes-Carvalho, C. F. Marinho, L. M. de Oliveira-Pinto et al., "Regulation of $\mathrm{T}$ lymphocyte apoptotic markers is associated to cell activation during the acute phase of dengue," Immunobiology, vol. 219, no. 5, pp. 329-340, 2014. 


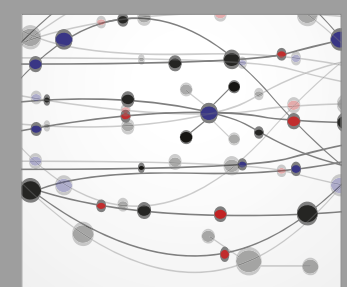

The Scientific World Journal
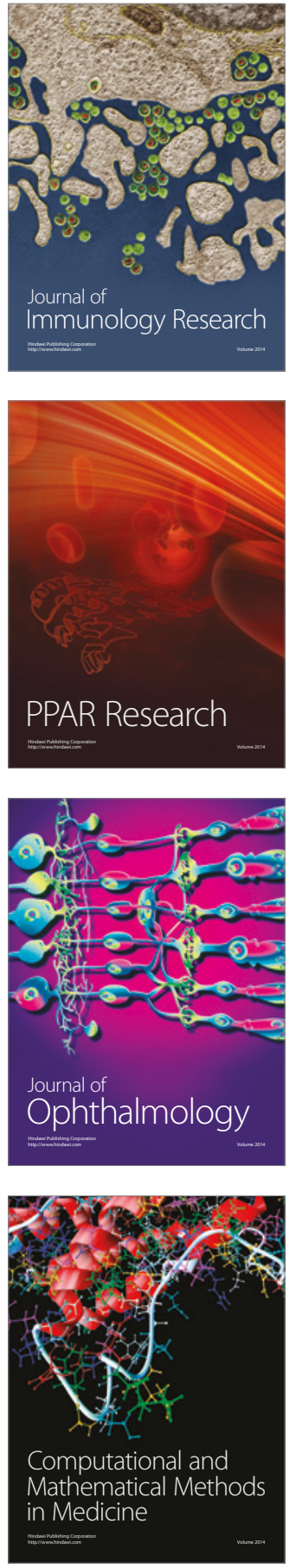

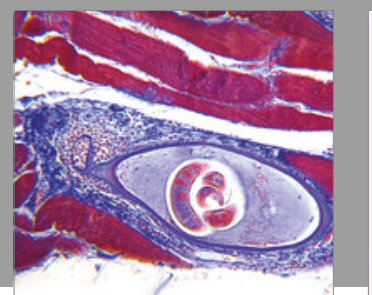

Gastroenterology Research and Practice
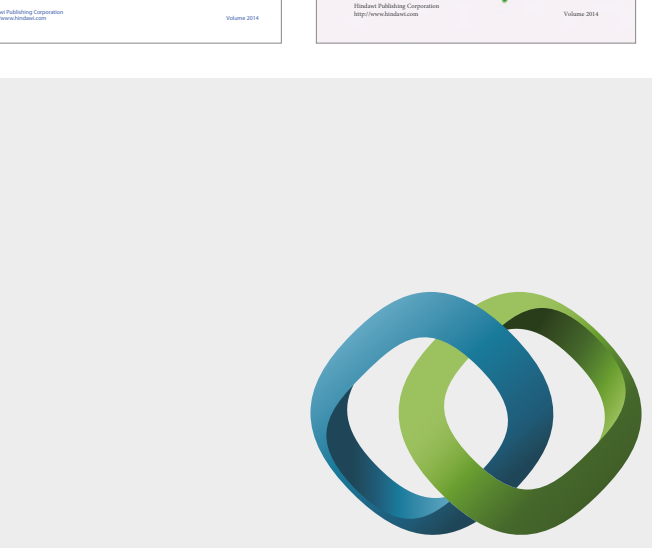

\section{Hindawi}

Submit your manuscripts at

https://www.hindawi.com
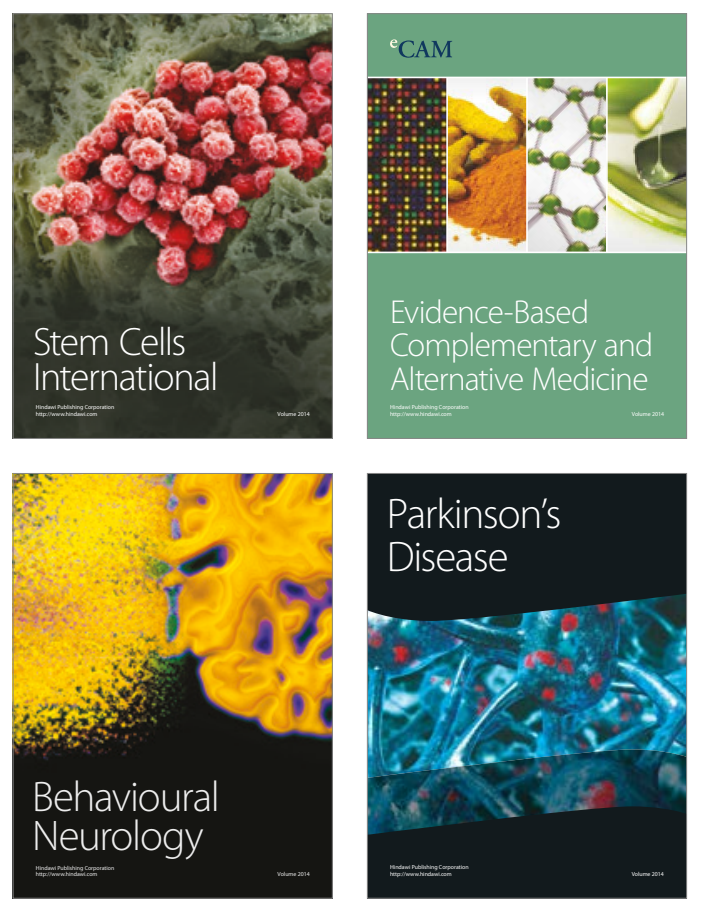
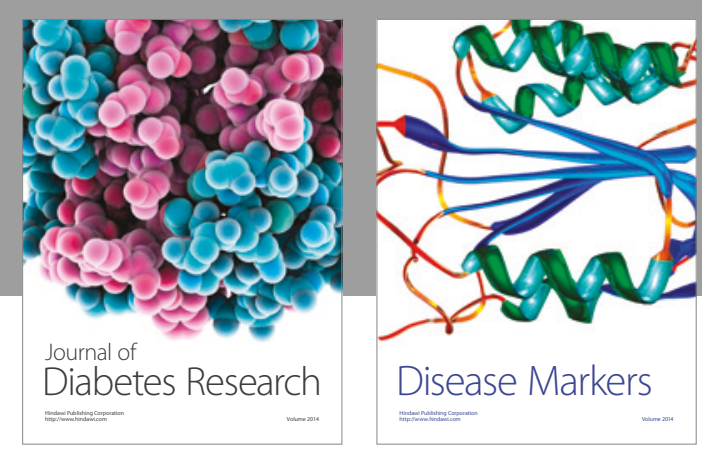

Disease Markers
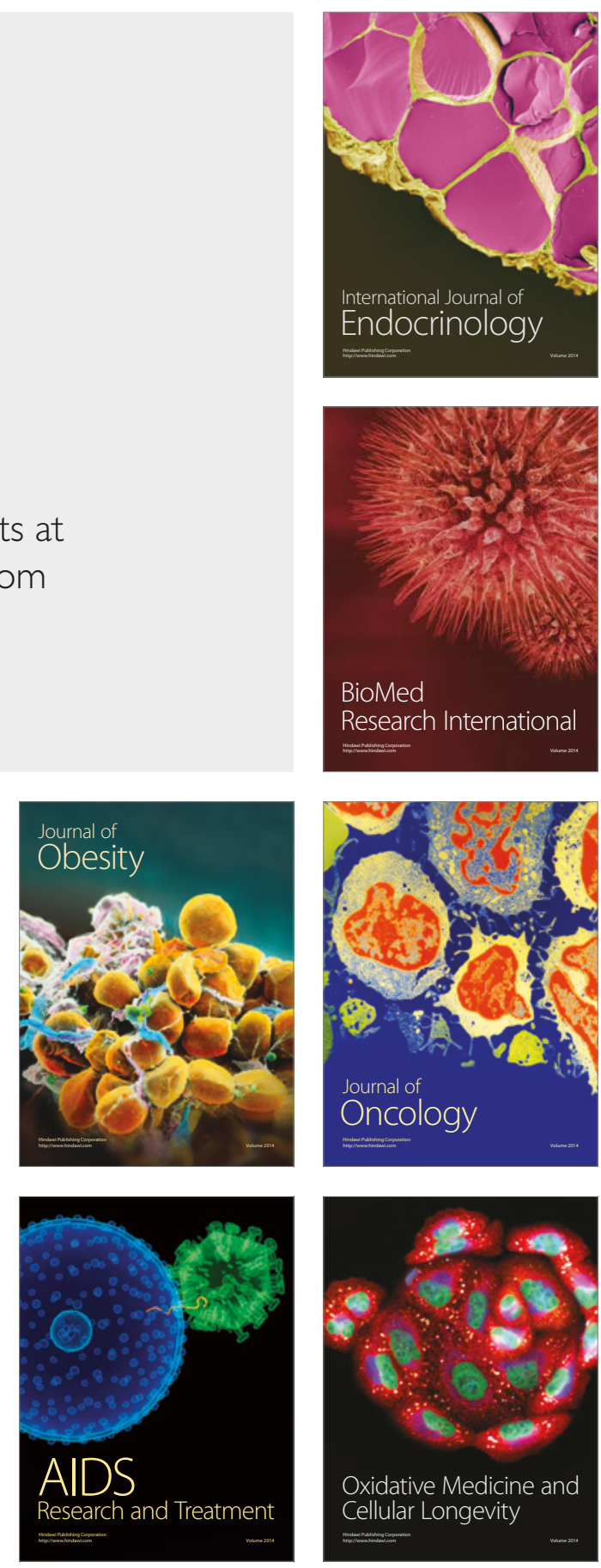